\title{
Estudo da interceptação da água de chuva em cobertura florestal amazônica do tipo terra firme
}

\author{
Wolfram Franken ('), Paulo Rodolfo Leopoldo $\left({ }^{2}\right)$, Eiichi Matsui $\left({ }^{3}\right)$ e Maria de Nazaré Goes Ribeiro (')
}

Resumo

Em experimento conduzido junto à Reserva Florestal Ducke, situada a cerca de $26 \mathrm{~km}$ da cidade de Manaus, quantificou-se a parcela da água de chuva interceptada pela cobertura florestal. No seu desenvolvimento, foram empregados um pluviócrafo, localizado a $20 \mathrm{~m}$ da floresta e 20 pluviômetros instalados no interior da mata. Os resultados obtidos mostraram que, do total da chuva precipitada no período, cerca de $19,8 \%$, em média foram interceptados pela cobertura florestal.

\section{INTRODUÇÃo}

O estudo da perda por interceptação da água de chuva em cobertura Florestal Amazônica torna-se importante, uma vez que toda parcela interceptada, retorna à atmosfera por evaporação, voltando a fazer parte da massa de vapor d'água contribuindo para novas precipitações na Região (Salati et al., 1979) .

Experimento realizado em área da Bacia Modelo, junto ao km 14 da ZF-2, demonstrou-se que $22 \%$ do total da chuva foram retidos pela cobertura florestal, $77,7 \%$ atingiram o solo na forma de precipitação interna, enquanto que, uma pequena parcela, $d a$ ordem de $0.3 \%$, representou o escoamento pelo tronco (Franken et al., s/d) .

Em estudos semelhantes, conduzidos em floresta tropical situada na Malásia, observouse que, em função da precipitação, as perdas por interceptação atingiam valores que podiam variar de $25 \%$ a $80 \%$ do total da chuva (Sim. 1972), enquanto que valores de apenas $5 \%$ foram obtidos para as condições de Floresta Amazônica da Venezuela, na região de San Carlos de Rio Negro (Jordan \& Heuveldop, 1981).
Para florestas homogêneas, constituídas artificialmente, verifica-se que a perda por interceptação é um valor que depende sobretudo da idade e espaçamento do povoamento, bem como da essência florestal utilizada no reflorestamento (Rutter, 1963; Karschon \& Helth, 1967; Lima. 1976) .

A perda por interceptação, no caso de culturas anuais, é fundamentalmente dependente do estágio de desenvolvimento da vegetação do que propriamente da quantidade de chuva (Leo. poldo et al., 1981).

A parcela da água de chuva que representa a perda por interceptação é um componente importante do ciclo hidrológico, e que, no caso da região Amazônica, dada a extensão da cobertura florestal, deve responder com a introdução de consideráveis quantidades de massa de vapor d'água na atmosfera, as quais através de sua recirculação atuam no equilíbrio hídrico na região.

O estudo foi realizado, tendo-se em vista a quantificação da perda por interceptação da água de chuva, em Floresta Amazônica do tipo terra-firme, em local próximo a Manaus, comparando-se os resultados com outros obtidos para a região através de semelhantes estudos.

\section{MATERIAIS E MÉTodos}

O experimento foi realizado na Reserva Ducke, dc INPA, situada a cerca de $26 \mathrm{~km}$ de Manaus, junto à rodovia Manaus-Itacoatiara. A vegetação do local é caracterizada por cobertura florestal amazônica do tipo terra-firme.

Na quantificação da perda por interceptação, empregou-se a equação definida por $\mathrm{Hel}$ vey \& Patric (1965):

$$
\mathrm{I}=\mathrm{PT}-(\mathrm{PI}+\mathrm{Et}) \ldots \ldots \ldots \ldots
$$

(1) - Instituto Nacional de Pesquisas da Amazônia, Manaus.

(2) - Faculdade de Ciências Agronômicas, UNESP, Botucatu, SP,

(3) - Centro de Energia Nuclear na Agricultura, USP, Piracicaba, SP. 
onde 1 = perda por interceptação;

PT $=$ quantidade de chuva que chega até o topo das copas das árvores;

$\mathrm{Et}=$ escoamento pelo tronco $\mathrm{e}$

PI = precipitação interna, ou seja, parcela da água de chuva que diretamente ou por respingos chega à superfície do solo.

O termo Et foi desprezado, tendo-se em vista que o seu valor não é representativo quando comparado aos demais termos da equação (1) (Franken et al., s/d).

$\mathrm{Na}$ determinação do valor de PT, empregouse um pluviógrafo de $200 \mathrm{~cm}^{2}$ de superfície de captação, localizado a $20 \mathrm{~m}$ da floresta. 0 termo PI foi estimado através da média de 20 pluviômtros de $100 \mathrm{~cm}^{2}$ de superfície de captação, cada um, e instalados no interior da mata. As leituras desses pluviômetros foram feitas em intervalos semanais.

No decorrer do experimento, realizado no período de $16 / 11 / 76$ a $19 / 12 / 77$, foram feitas 49 observações.

\section{REsultados}

$\mathrm{Na}$ Tabela 1, apresentam-se os resultados obtidos na forma de valores médios de precipitação interna e perda por interceptação observados em função das classes de altura de chuva, calculados em termos milimétricos e percentuais.

A Tabela 2 miostra uma relação entre o total de chuva ocorrida no período de 16/11/76 a $19 / 12 / 77$ e as parcelas correspondentes à precipitação interna e perda por interceptação, em valores milimétricos e percentuais.

$\mathrm{Na}$ Fig. 1, tem-se a curva de regressão para os valores da precipitação interna em função dos valores observados para a precipitação total, válida para o intervalo de 4 a $165 \mathrm{~mm}$. Nesta figura, incluem-se a respectiva equação de regressão e os valores dos coeficientes $r$ e $r^{2}$. A Fig. 2 mostra a curva de regressão para os valores da percentagem de perda por interceptação em função dos valores médios da precipitação total observados em cada classe da altura de chuva, incluindo-se a respectiva equação, os valores de $r$ e $r^{2}$.
TABELA 1 - Valores médios de precipitação interna e perda por interceptação calculada, observados em função das classes de tamanhos de chuva, dados em milímetros e em valores percentuais.

\begin{tabular}{ccrrrr}
\hline $\begin{array}{c}\text { Classes de PT } \\
\text { mm }\end{array}$ & Freqüência & \multicolumn{2}{c}{ PI } & \multicolumn{2}{c}{ I } \\
& & $\mathrm{mm}$ & $\%$ & $\mathrm{~mm}$ & $\%$ \\
\hline & & & & & \\
$10-10$ & 4 & 4,1 & 66,1 & 2,1 & 33,9 \\
$20-30$ & 7 & 10,9 & 77,9 & 3,1 & 22,1 \\
$30-40$ & 9 & 20,5 & 81,3 & 4,7 & 18,7 \\
$40-50$ & 4 & 31,3 & 91,5 & 2,9 & 8,5 \\
$50-60$ & 2 & 36,1 & 81,9 & 8,0 & 18,1 \\
$60-70$ & 7 & 47,4 & 84,3 & 8,4 & 15,2 \\
$70-80$ & 3 & 53,8 & 83,2 & 10,9 & 16,8 \\
$80-100$ & 5 & 56,5 & 85,6 & 11,0 & 14,4 \\
$>100$ & 5 & 111,9 & 83,0 & 15,3 & 17,0 \\
\hline 0 & 5 & & 27,2 & 19,6 \\
\hline
\end{tabular}

TABELA 2 - Valores observados para a precipitação total, precipitação interna e perda por interceptação calculada, em milímetros e valores percentuais, para o período de 16.11.76 a 19.12.77.

\begin{tabular}{rrrr}
\hline & \multicolumn{1}{c}{ PT } & \multicolumn{1}{c}{ PI } & \multicolumn{1}{c}{ I } \\
\hline $\mathrm{mm}$ & $2.570,4$ & $2.061,5$ & 508,9 \\
$\%$ & 100,0 & 80,2 & 19,8 \\
\hline
\end{tabular}

\section{DISCUSSÃo}

Os resultados obtidos em linhas gerais, são muito próximos dos observados por Franken et al. (s/d), no qual a perda por interceptação foi estimada em $22 \%$ do total da chuva.

Neste trabalho, de acordo com a Tabela 2, verifica-se que a perda por interceptação foi calculada como sendo da ordem de $19,8 \%$, sem considerar-se a percentagem escoada pelo tronco, que segundo aqueles autores, é um valor passível de ser desprezado, uma vez que os erros cometidos nas leituras superam os seus próprios valores.

Essa pequena diferença de $2,2 \%$, provavelmente, se deve às diferentes quantidades de chuva obtidas nos dois experimentos, conduzidos em ocasiões distintas. Verifica-se que naquele desenvolvido junto à Bacia Modelo, na $\mathrm{ZF}-2$, as chuvas semanais, em sua maior parte, 
se situaram no intervalo de 3 a $70 \mathrm{~mm}$. Neste, as chuvas se situaram, em sua maior parte, no intervalo de 4 a $100 \mathrm{~mm}$, conforme pode ser visto na Figura 1. Observa-se, portanto, que os comportamentos das coberturas florestais dos dois locais, em relação à quantidade de chuva interceptada, são praticamente semelhantes.

Pela Tabela 1, verifica-se que os valores médios da precipitação interna, dados em milímetros, aumentam com o total da chuva. Essa observação já foi ressaltada por vários autores, entre eles Aussenac (1968) e Lima (1976). Em termos percentuais médios, no entanto, há uma certa tendência em tornarem-se constantes, principalmente, para as classes de altura de chuva acima de $20 \mathrm{~mm}$, quando a precipitação interna assume valores maiores que $80 \%$ dc total cia chuva. Neste aspecto, o valor obtido para a classe de 30 a $40 \mathrm{~mm}$, com $91,5 \%$, foi discrepante em relação às demais classes. Essa verificação sugere que, as chuvas ocorridas no intervalo de 30 a $40 \mathrm{~mm}$ diferiram, em termos de intensidade, duraçäo e outros fatores, das demais observadas.

[)e acordo com a curva de regressão, vista na Figura 1, tem-se peio valor de $r^{2}$ que cerca de $98 \%$ da precipitação interna pode ser explicado pela quantidade de chuva total, muito embora ocorram certas variações de evento para evento. Neste aspecto, a discussão contida em Franken et al. (s/d), na qual se ressaita o tipo de chuva que normalmente ocorre na região, é também válida.

Através da Fig. 2, observa-se que a percentagem de perda por interceptação tende a di. minuir com o aumento da altura de chuva até

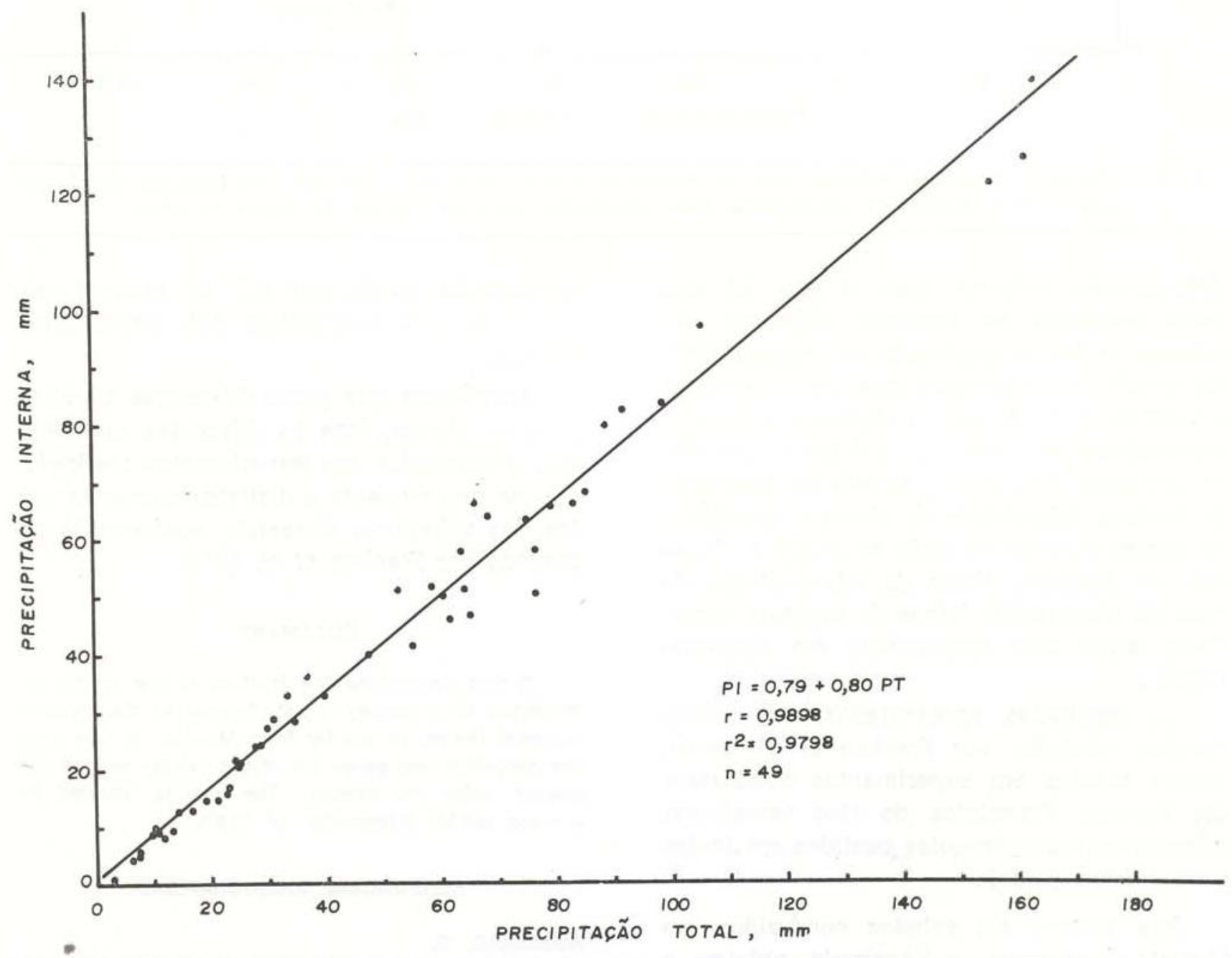

Fig. 1 - Curva de regressão para os va.ores da precipitaçáo interna em tunção dos valores observados para a precipitação total, válida para o intervalo de 4 a $165 \mathrm{~mm}$ de chuva. 


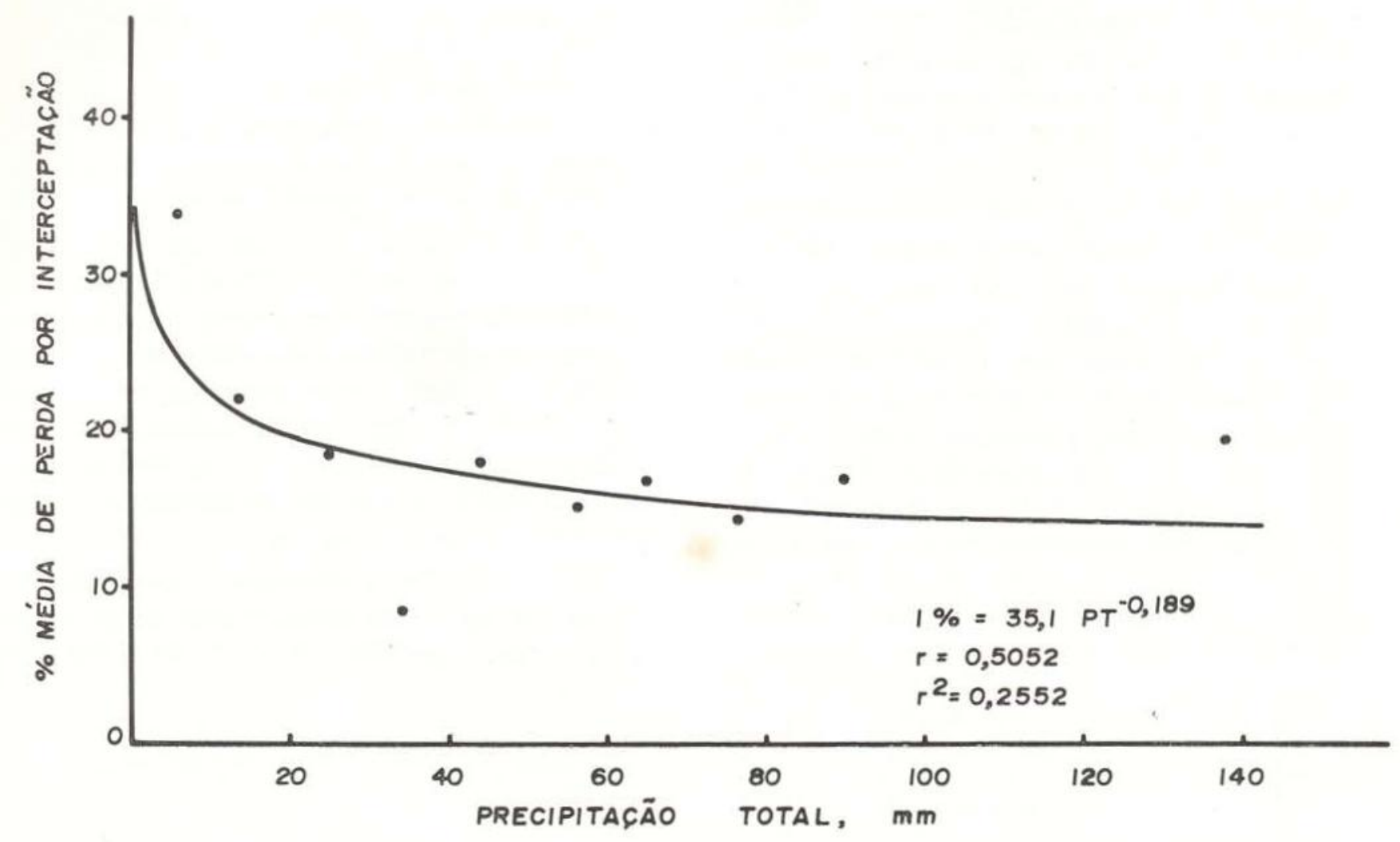

Fig. 2 - Curva de regressão estimada para os valores da porcentagem de perda por interceptação em função dos valores médios de precipitação total observados para as classes de altura de chuva.

determinados valores, após o que, há uma certa tendência em tornar-se constante. No entanto, o fato é explicado em apenas $26 \%$. em função da precipitação total, de acordo com o valor de $r^{2}$ obtido para a regressão estimada, demonstrando-se que outros fatores intervêm no processo tais como, estado de saturação da floresta, intensidade de chuva e ocorrência de ventos durante ou após os eventos chuvosos. O processo físico da interceptação da água de chuva pelas folhas de vegetais encontra-se muito bem apresentado em Aussenac (1968) .

Os resultados apresentados, bem como aqueles relatados por Franken et al. (s/d), ambos obtidos em experimentos conduzidos em Floresta Amazônica do tipo terra-firme, diferem em muito daqueles contidos em Jordan \& Heuveldop (1981).

Tais autores em estudos conduzidos em Floresta Amāzónica da Venezuela, próxima à regiâo de San Carlos, concluiram que apenas $5 \%$ da precipitação total são perdidos por in- terceptação, sendo que $8 \%$ se escoam pelo tronco e $87 \%$ respondem pela precipitação interna.

Acredita-se que essas diferenças significativas se deram, face às diferentes metodologias empregades nos experimentos realizados do que propriamente a distintos comportamentos das coberturas florestais, conforme já observado por Franken et al. (s/d).

\section{SUMMARY}

It was determined the fraction of the rainfall intercepted by a canopy forest, located at the Reserva Florestal Ducke, $26 \mathrm{~km}$ far from Manaus. It was used one recording rain gauge out of the canopy and 20 rain gauges under the canopy. The results showed an average rainfall interception of $19,8 \%$.

\section{REFERENCIAS BIBLIOGRÁFICAS}

AUSSENAC, G.

1968 - Interception des précipitations par le coverture forestier. Ann. Sci. forest, 25 (3): 135-156. 
FRANKEN, W.; LEOPOLDO, P.R.; MATSUI, E.; RIBEIRO, M.N.G.

s/d - Interceptação das precipitações em floresta amazônica de terra-firme. Acta Amazonica. Suplemento (no prelo).

HELVEY, J.D. \& PATRIC, J.H.

1965 - Design criteria for interception studies. International Association. Science Hydrology, Boletim (7): 131-137.

JORDAN, C.F. \& HEUVELDOP, J.

1981 - The water budget of an amazonian rain forest. Acta Amazonica, 11 (1): 87-92.

KARSCHON, R. \& HELTH, D

1967 - The water balance of a plantation of Eucalyptus camaldulensis. Ilanot, 3: 7-34.

LEOPOLDO, P.R.; SOUSA, A.P. \& TUACEK $F^{\circ}$, S.

1981 - Interceptação da água de chuva em cultura de canł-de-açúcar. Brasil Açucareiro, 98 (6): 9-16.
LIMA, W. de P.

1976 - Interceptação da chuva em povoamento de eucalipto e pinheiro. IPEF, Piracicaba, 13: 75-90.

RUTTER, A.J.

1963 - Studies in the water relations of Pinus sylvestris in plantation conditions: $1-$ messurements of rainfall and interception. Journal of Ecology, 51: 191-203.

SALATI, E.; DALl'OliO, A.; MATSUI, E.; GAT, J.

1979 - Recycling of water in the Amazon Basin: an isotopic study. Water Resources Research, 15 (5): 1250-1258.

SIM, L.K.

1972 - Interception loss in the humid forested areas. Malayan Nature Journal, 25 (2): 104-111.

(Aceito para publicação em 28/04/82) 